\title{
Peningkatan Soft Skill Siswa SMK PGRI Kediri MelaluiPelatihan Zahir Accounting
}

\author{
Erna Puspita ${ }^{*}$, Puji Astuti, Andy Kurniawan, Hestin Sri Widiawati, Linawati, Diah \\ Nurdiwaty \\ Akuntansi, FakultasEkonomi dan Bisnis, Universitas Nusantara PGRI Kediri \\ Jl. KH. Achmad Dahlan No. 76 Mojoroto, Kediri \\ *Email: ernapuspita@unpkediri.ac.id
}

\begin{abstract}
This activity aims to increase the knowledge and soft skills of SMK students regarding accounting software. Students are given knowledge, understanding, and training to update accounting software from the software MYOB to Zahir Accounting, which is more developed following changes in accounting science and the needs of the modern business world. The activity was carried out at SMK PGRI 3 Kediri City. The participants of the exercise were students of SMK class XII. Implementation of activities in the form of training. The method of implementing the conditioning is done through lectures, practicum, and question and answer. The action is divided into two sessions. In the first session, the material explained Zahir Accounting software. In the second session, the Zahir Accounting software practicum was held, where participants could practice the accounting cycle directly using Zahir Accounting software. The participants participated in the training activities in a conducive and enthusiastic manner. The participants had no difficulty in implementing the training.
\end{abstract}

Keywords

Zahir Accounting software, accounting cycle.

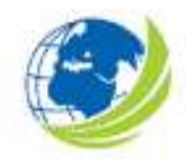

BERDAYA : Jurnal Pendidikan dan Pengabdian

Kepada Masyarakat Vol 3, No.3, Desember 2021, pp.103 - 110 eISSN 2721-6381

\section{Article History}

Received 24 Oct 2021 / Accepted 20 Nov 2021 / First Published: 16 Dec 2021

To cite this article

Puspita, E., Astuti, P., Kurniawan, A., Widiawati, H., Linawati, L., \& Nurdiwaty, D. (2021). PeningkatanSoft SkillSiswa SMK PGRI Kediri MelaluiPelatihanZahir Accounting. BERDAYA: Jurnal Pendidikan Dan Pengabdian Kepada Masyarakat, 3(3), 103 - 110

DOI: $10.36407 /$ berdaya.v3i3.453

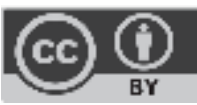

(C) The Author(s)2021

. This open access article is distributed under a Creative Commons Attribution (CC-BY) 4.0 license 


\begin{abstract}
ABSTRAK
Kegiatan ini bertujuan untuk menambah pengetahuan dan soft skill siswa SMK mengenai software akuntansi. Siswa diberikan pengetahuan dan pemahaman, serta pelatihan untuk meng-update software akuntansi dari softwaredari MYOB ke Zahir Accounting yang lebih berkembang mengikuti perubahan ilmu akuntansi dan kebutuhan dunia bisnis modern. Kegiatan dilaksanakan di SMK PGRI 3 Kota Kediri. Peserta kegiatan adalah siswa SMK kelas XII. Pelaksanaan kegiatan berbentuk pelatihan. Metode pelaksanaan kegiatan dilakukan melalui ceramah, praktikum, dan tanya jawab. Kegiatan dibagi dalam 2 sesi. Pada sesi pertama, penjelasan materi tentang softwareZahir Accounting. Pada sesi kedua dilaksanakan praktikum software Zahir Accounting, dimana para peserta dapat berpraktik secara langsung siklus akuntansi menggunakan software Zahir Accounting. Para peserta mengikuti kegiatan pelatihan dengan kondusif dan penuh antusias. Para peserta tidak mengalami kesulitan dalam pelaksaaan pelatihan.
\end{abstract}

Kata Kunci : software Zahir Accounting, siklus akuntansi
Profil Penulis

Erna Puspita, Puji Astuti, Andy

Kurniawan, Hestin Sri Widiawati, Linawati, Diah Nurdiwaty

Akuntansi, FakultasEkonomi dan Bisnis, Universitas Nusantara PGRI

Kediri

Jl. KH. Achmad Dahlan No. 76 Mojoroto, Kediri

\section{Korespondensi:}

Erna Puspita

Akuntansi, FakultasEkonomi dan Bisnis, Universitas Nusantara PGRI

Kediri

Email: ernapuspita@unpkediri.ac.id

Reviewing Editor

Swarmilah Hariani, Universitas Mercu Buana, Jakarta

\section{PENDAHULUAN}

Sistem informasi berbasis komputer merupakan kebutuhan utama dalam dunia bisnis, dengan adanya sistem dapat menghasilkan informasi dalam waktu yang singkat dengan tingkat akurasi lebih tinggi apabila dibandingkan dengan sistem manual. Pada saat ini kita dituntut untuk bisa mengembangkan keahlian di bidang komputer secara terus menerus sesuai mengikuti perkembangan teknologi. Teknologi memberikan nilai tambah bagi organisasi (Damayanti et al., 2018)

Salah satu sistem informasi yang penting bagi dunia usaha adalah penggunaan program atau software akuntansi dalam melakukan transaksi bisnis. Dengan demikian, penggunaan program akuntansi adalah kebutuhan mendasar untuk menjalankan suatu bisnis. Dengan software akuntansi, seluruh aspek bisnis yang dikelola dapat diukur secara tepat waktu, tanpa harus menunggu selesainya laporan yang harus dibuat secara manual dan memakan waktu lebih lama. Mengingat informasi akuntansi sangat penting bagi aktivitas perusahaan atau manajemen dalam pengambilan keputusan. Penggunaan software akuntansi tentu mempermudah dan mempercepat penyusunan laporan keuangan yang baik dan akuntabel (Ria \& Zainuddin, 2021).

Merujuk permasalahan di atas, peserta didik sangat perlu dibekali ilmu terkait software akuntansi, sehingga bisa memahami dan mampu mengoperasikan software akuntansi agar memiliki bekal siap kerja di dalam dunia bisnis. Sangatlah kurang sempurna, apabila peserta didik hanya dibekali pengetahuan teoritis tanpa diserta praktikum mengoperasikan software akuntansi. 
Software akuntansi terus berkembang dari waktu ke waktu mengikuti kebutuhan dan perkembangan dunia bisnis. Saat ini software akuntansi yang dipakai oleh siswa Jurusan Akuntansi di SMK PGRI 3 Kota Kediri adalah MYOB Accounting Versi 19. Aplikasi ini sudah cukup jauh tertinggal dan tidak lagi sesuai dengan perkembangan ilmu akuntansi. Diantara kekurangan dari MYOB Accounting Versi 19 ini adalah 1) Tidak dapat digunakan untuk mengelola perusahaan dengan multi company, artinya MYOB tidak dapat membuat laporan konsolidasi, 2) Database MYOB merupakan file based, sehingga kurang optimal jika digunakan untuk transaksi yang besar dan kompleks, 3) Belum mendukung multi Gudang, sehingga sulit diterapkan pada perusahaan yang memiliki lebih dari 1 gudang. Berdasarkan berbagai alasan di atas, dirasa sangat perlu melakukan apdate software akuntansi selain MYOB. Software akuntansi yang dapat menjawab kekurangan tersebut, yaitu software Zahir Accounting. Software Zahir Accounting telah banyak digunakan oleh perusahaan besar di berbagai negara.

Zahir Accounting digunakan oleh lebih dari duaribu perusahaan kecil maupun perusahaan besar dengan enamribu user di Indonesia, juga telah memperoleh banyak penghargaan tingkat nasional (Ganyang et al., 2021). Zahir Accounting merupakan software akuntansi yang terus berkembang dan mengikuti perkembangan ilmu akuntansi. Software ini merupakan software manajemen bisnis yang memberikan kemudahan dalam mengelola dan menyajikan laporan keuangan dari berbagai aktivitas bisnis. Beberapa kelebihan dari zahir accounting adalah mudah digunakan, desain user interface menarik dan mudah dipahami, faktur dan laporan dapat didesain, laporan dapat diemail dan diexport ke berbagai format, menggunakan database client server, fasilitas dan kapasitas dapat dipilih sesuai dengan kebutuhan user, terdapat berbagai grafik dan Analisa bisnis yang interaktif, laporan dapat diklik untuk melihat detail transaksi terkait, dan memiliki berbagai opsi fasilitas advance. (Rachmawati et al., 2021)

\section{Sasaran Kegiatan}

Kegiatan ini ditujukan untuk siswa jurusan akuntansi di SMK PGRI 3 Kota Kediri yang beralamat di Jalan KH. Achmad Dahlan Mojoroto Gg. 1 No. 6 Kediri.

\section{Masalah yang ingin dipecahkan}

Software akuntansi terus berkembang dari waktu ke waktu mengikuti kebutuhan dan juga perkembangan ilmu akuntansi itu sendiri dan dunia bisnis saat ini. SMK PGRI 3 Kota Kediri saat ini dalam proses pembelajaran menggunakan software akuntansi MYOB Accounting Versi 19, yang mana software ini memiliki beberapa kekurangan khususnya di era perkembangan bisnis saat ini. Oleh karena itu, dirasa perlu untuk melakukan update pengetahuan dan keterampilan software akuntansi, khususnya dari software MYOB ke Zahir Accounting yang lebih berkembang mengikuti perubahan ilmu akuntansi dan kebutuhan dunia bisnis modern.

\section{Materi}

\section{MATERI DAN METODE}

Materi yang disampaikan dalam kegiatan ini diantaranya adalah mengenal Zahir Accounting mulai dari penjelasan menu-menu yang ada di dalamnya, membuat data base perusahaan baru, membuat data customer dan vendor, membuat data persediaan, melakukan input saldo awal akun, saldo awal utang dan piutang, juga saldo awal persediaan, melakukan input transaksi keuangan sampai pada praktik menyusun laporan keuangan. 


\section{Lokasi Kegiatan}

Lokasi kegiatan adalah di SMK PGRI 3 Kota Kediri yang beralamat di Jalan KH. Achmad Dahlan Mojoroto Gg. 1 No. 6 Kediri. Pelaksaan kegiatan berlangsung pada 21 Oktober 2021. Peserta kegiatan ini adalah siswa jurusan akuntansi khususnya kelas XII di SMK PGRI 3 Kota Kediri

\section{Prosedur dan Metode}

Pelaksanaan kegiatan berbentuk pelatihan. Pelaksanaan kegiatan ini menggunakan tiga metode, yaitu ceramah, praktikum, dan tanya jawab. Metode pertama adalah ceramah, metode ini dilakukan dengan mengombinasikan laptop dan LCD Proyektor yang digunakan untuk menjelaskan materi tentang pengenalan software Zahir Accounting, fitur-fitur yang ada di dalamnya serta kelebihan yang dimiliki oleh Zahir Accounting.

Metode kedua adalah praktikum, digunakan agar peserta yaitu siswa SMK PGRI 3 Kota Kediri lebih memahami bagaimana siklus akuntansi menggunakan software Zahir Accounting. Mulai dari membuat database perusahaan baru, membuat data customer dan vendor, membuat data persediaan, melakukan input saldo awal akun, saldo awal utang dan piutang, juga saldo awal persediaan, melakukan input transaksi keuangan sampai pada praktik menyusun laporan keuangan. Terakhir, metode tanya jawab digunakan untuk menjawab permasalahan atau kesulitan yang dialami oleh peserta pada saat praktikum berlangsung dan materi mengenai software Zahir Accounting.

\section{HASIL DAN PEMBAHASAN}

\section{Pelaksanaan Kegiatan}

Pelaksanaan kegiatan pelatihan softwareZahir Accounting dilaksanakan pada tanggal 21 Oktober 2021 dari pukul 08.00 sampai dengan pukul 12.20 WIB, bertempat di SMK PGRI 3 Kota Kediri. Kegiatan pelatihan diikuti oleh siswa kelas XII yang berjumlah 19 siswa. Tim kegiatan pelatihan ini merupakan dosen dan mahasiswa Prodi Akuntansi UNP Kediri, yang menyampaikan materi, merespon pertanyaan, dan mendampingi peserta saat pelatihan berlangsung. Pelaksanaan kegiatan pelatihan diikuti secara tertib, kondusif, dan antusias oleh para peserta.

Kegiatan pelatihan dibagi dalam 2 sesi. Sesi pertama dilaksanakan pemaparan materi tentang software Zahir Accounting. Penyajian dilakukan dengan metode ceramah melalui media proyektor LCd untuk menjelaskan materi. Para peserta juga diberikan bahan materi pelatihan, hal ini dilakukan untuk memudahkan para peserta dalam memahami materi software Zahir Accounting. Pada sesi kedua, para peserta diminta untuk praktik langsung dengan software Zahir Accounting. Tim melakukan pendampingan secara langsung pengerjaan siklus akuntansi menggunakan software Zahir Accounting. Berikut ini jadwal pelaksanaan pelatihan softwareZahir Accounting:

\section{Tabel 1.}

Jadwal kegiatan pelatihan

\begin{tabular}{lll}
\hline Waktu & Kegiatan & Pelaksana \\
\hline $08.00-08.30$ & Registrasi peserta & Peserta \\
$08.30-08.40$ & Sambutan Kepala SMK PGRI 3 Kota Kediri & Kepala SMK PGRI 3 \\
& & Kota Kediri \\
$08.40-08.50$ & Sambutan Ketua Tim Pengabdian Masyarakat Prodi & Ketua Tim \\
$08.50-10.00$ & Akuntansi & Tim Pengabdian \\
$10.00-12.00$ & Sesi I : Pemaparan materi softwareZahir Accounting & Tim Pengabdian \\
& $\begin{array}{l}\text { Sesi II : Praktikum siklus akuntansi menggunakan } \\
\text { softwareZahir Accounting }\end{array}$ \\
\hline
\end{tabular}


Zahir Accounting software, accounting cycle.

$12.00-12.20 \quad$ Penutup pelatihan dan dokumentasi

Peserta, Guru, Tim

Pengabdian

\section{Evaluasi Kegiatan}

Evaluasi kegiatan pelatihan dilakukan secara langsung dan tergabung pada saat pelaksanaan pelatihan berlangsung. Evaluasi kegiatan dilakukan untuk melihat keberhasilan pelatihan dengan indikator peningkatan pengetahuan dan pemahaman peserta, serta kemampuan menggunakan software Zahir Accounting. Kegiatan pelatihan software Zahir Accounting berjalan dengan lancar dan sesuai dengan yang diharapkan. Para peserta mampu memahami dengan cepat materi tentang softwareZahir Accounting. Para peserta dapat mempraktikkan dengan cepat dan tidak mengalami kesulitan yang berarti. Hal ini dikarenakan para siswa yang berlatar belakang jurusan akuntansi, sehingga mudah untuk memahami siklus akuntansi dan mempraktikkannya. Antusiasme peserta dalam mengikuti pelatihan sangat tinggi, ditunjukkan dengan respon segera bertanya ketika ada yang kurang dipahami.

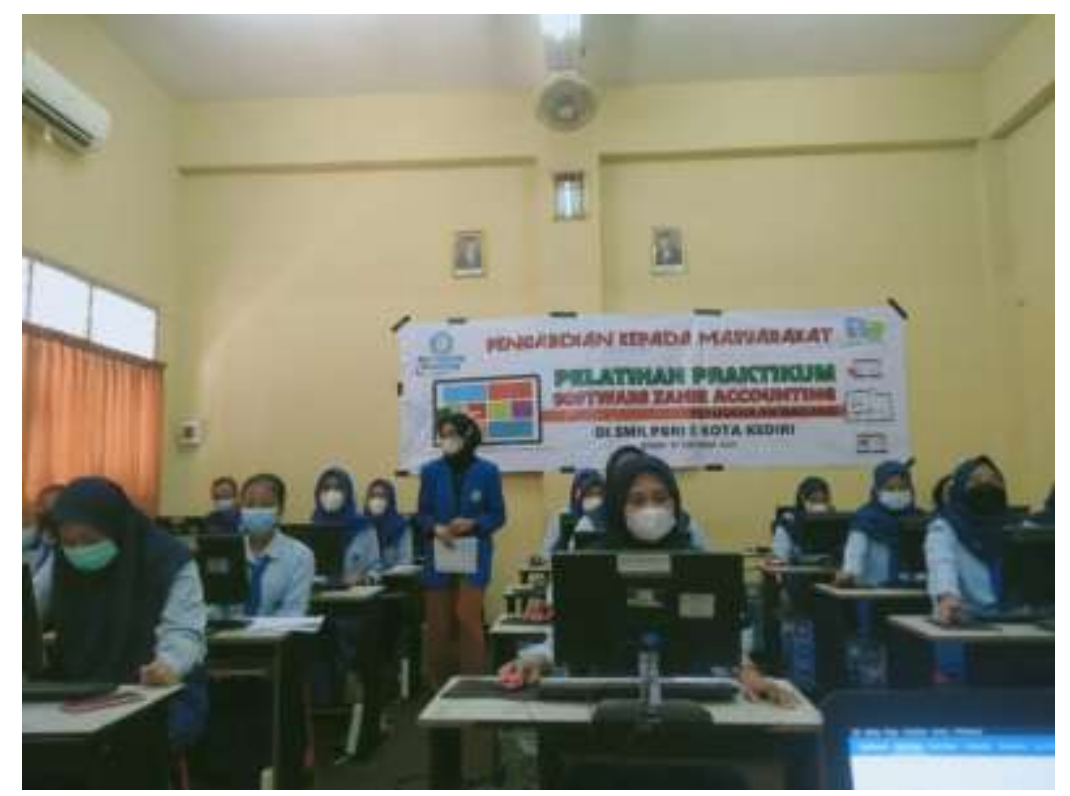

Gambar 1. Pesertapelatihan, antusias dalam mengikuti pelatihan.

Sumber: Dokumentasi

Tim Pelaksana (2021)

\section{Kesimpulan}

\section{KESIMPULAN}

Pelaksanaan kegiatan pelatihan berjalan dengan lancar dan berhasil. Ketercapaian pelaksaaan kegiatan pelatihan ditunjukkan antusiasme yang tinggi dari para peserta. Peserta pelatihan yang merupakan siswa SMK dapat meng-update pengetahuannya mengenai software akuntansi yang lebih memadai, yakni software Zahir Accounting. Para peserta dapat memahami dan mempraktikkan siklus akuntansi menggunakan software Zahir Accounting tanpa mengalami kesulitan.

\section{Saran kegiatan Lanjutan}

Berdasarkan kegiatan pelatihan yang telah dilaksanakan, diharapkan pihak sekolah dapat mengup date praktikum akuntansi menggunakan software Zahir Accounting. Diketahui bahwa softwareZahir Accounting, merupakan software akuntansi yang lebih berkembang dengan mengikuti perubahanilmu akuntansi dan kebutuhan dunia bisnis modern. 

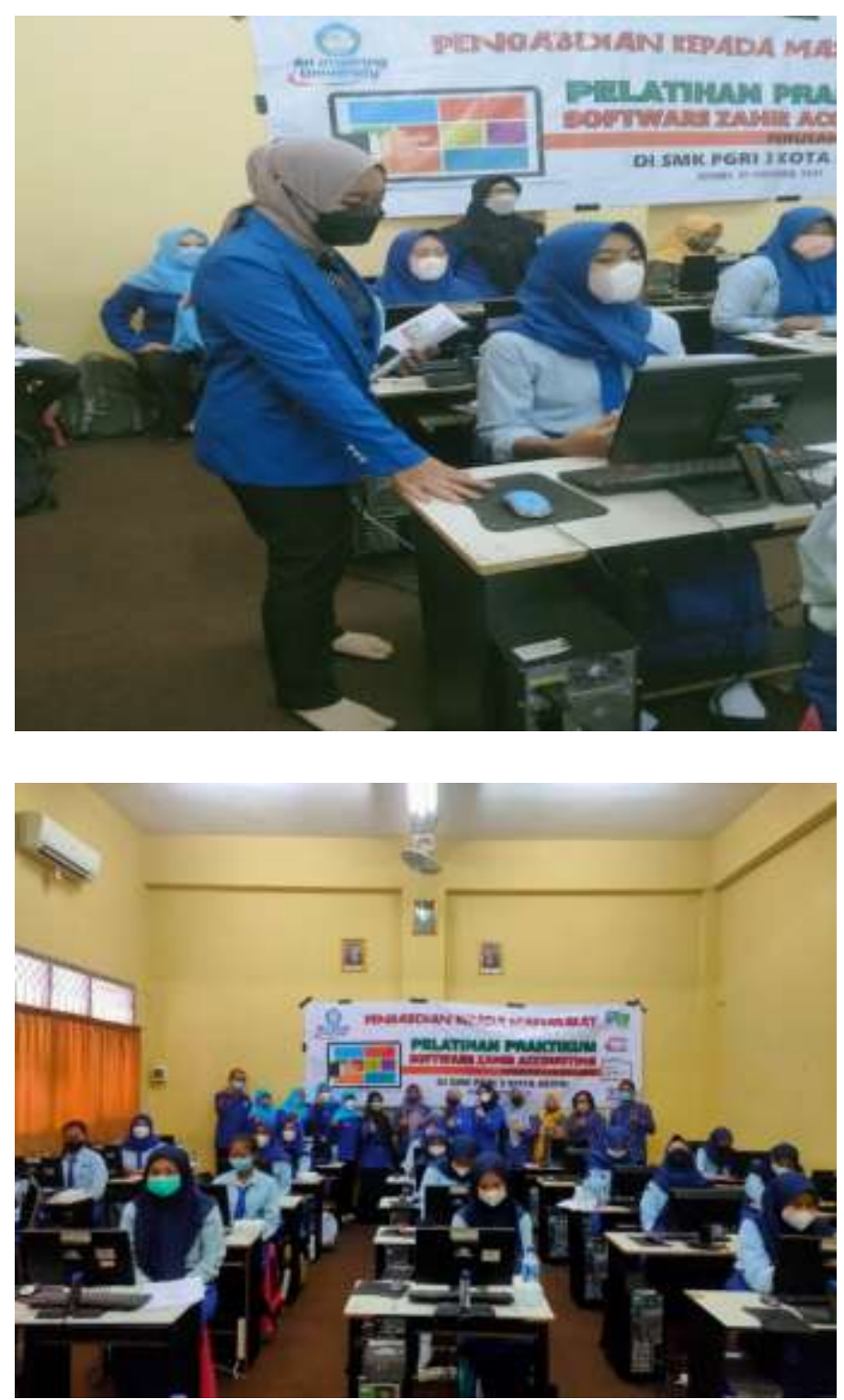

Gambar 2. Tim Pemateri mendampingi peserta pelatihan saat praktik.

Sumber: Dokumentasi Tim Pelaksana (2021)
Gambar 3. PesertaSiswa, Guru SMK PGRI 3 Kediri, dan Tim Pengabdian Prodi Akuntansi UNP Kediri.

Sumber: Dokumentasi Tim Pelaksana (2021)

\section{REFERENSI}

Damayanti, M., Ria, A., \& Zainuddin, D. (2018). Pengaruh Pelatihan Sertifikasi Zahir Accounting Terhadap Kesiapan Kerja Mahasiswa Program Studi Pendidikan Ekonomi. Seminar Nasional Dan Diskusi Panel Multidisiplin Hasil Penelitian \& Pengabdian Kepada Masyarakat, 212-216. http://proceeding.unindra.ac.id/index.php/dispanas2018/article/viewFile/42/31

Ganyang, M. T., Ritonga, W., \& Pbm, M. S. (2021). Pelatihan Akuntansi Berbasis Aplikasi untuk Mahasiswa Manajemen dan Akuntansi di Jakarta. BERDAYA, 3(2021), 67-74. https://doi.org/10.36407/ berdaya.v3i2.384

Rachmawati, S., Amalia, H., \& Retnasari, T. (2021). Efektifitas Pemanfaatan Aplikasi Zahir Accounting Dalam Pembuatan Laporan Keuangan Pada Rumah Tahfidz \& TPQ Sakinah. Abdimas Ekonomi Dan Bisnis, 1(1), 27. http://jurnal.bsi.ac.id/index.php/abdi-ekbis/article/view/252

Ria, A., \& Zainuddin, D. (2021). Pelatihan Pembuatan Laporan Keuangan Menggunakan SoftwareZahir Accounting pada Usaha Rintisan Yuk Takaful Depok. Reswara: Jurnal Pengabdian Kepada Masyarakat, 2, 331-338. 
Erna Puspita et al.

Zahir Accounting software, accounting cycle.

\section{About the Authors}

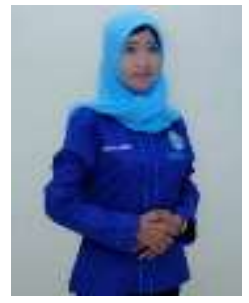

Erna Puspita, M.Ak. lahir di Nganjuk, 11 Desember 1988. Penulis merupakan dosen tetap prodi Akuntansi di Universitas Nusantara PGRI Kediri.

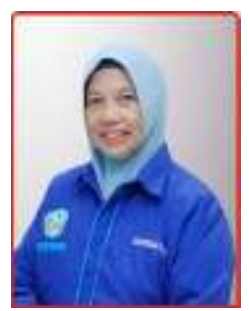

Dra. Puji Astuti, M.M. M.Si. Ak. CA. Penulis merupakan dosen tetap Prodi Akuntansi di Universitas Nusantara PGRI Kediri

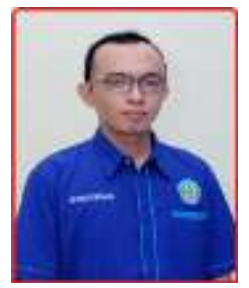

Andy Kurniawan, M.Ak. Penulis merupakan dosen tetap Prodi Akuntansi di Universitas Nusantara PGRI Kediri.

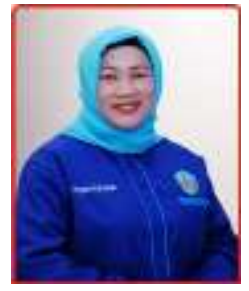

Hestin Sri widiawati, S.Pd., M.Si. Penulis merupakan dosen tetap Prodi Akuntansi di Universitas Nusantara PGRI Kediri.

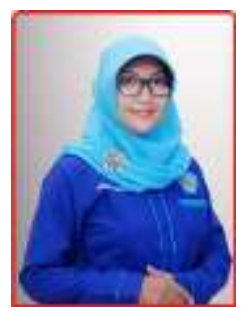

Linawati, S.Pd., M.Si. Penulis merupakan dosen tetap Prodi Akuntansi di Universitas Nusantara PGRI Kediri.

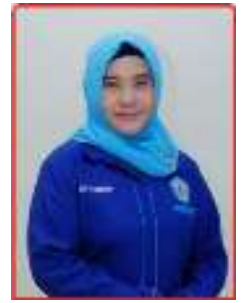

Diah Nurdiwaty, MSA. Penulis merupakan dosen tetap Prodi Akuntansi di Universitas Nusantara PGRI Kediri. 


\section{DECLARATIONS}

\section{Funding}

Kegiatan ini merupakan bagian dari program Pengabdian Kepada Masyarakat yang didanai oleh Dana Stimulus Pengabdian Pada Masyarakat, Universitas Nusantara PGRI Kediri, Tahun 2021.

\section{Competing Interests}

Tidak ada konflik kepentingan untuk diungkapkan. 